\title{
Papers
}

\section{Biological breakdown of wood in buildings}

Received: 27 th September, 2005

\section{Jørgen Bech-Andersen}

is the Head and Founder of Hussvamp Laboratoriet (the dry rot laboratory), Vedbæk. Prior to this he was Head of the Microbiological Laboratory at the Danish Technological Institute, Taastrup.

\begin{abstract}
A review is given of the role of fungi in nature and in buildings. The major groups of microorganisms are presented, and the living conditions of wood-decaying fungi regarding temperature and moisture are described. Both constructional and chemical methods of wood protection are options when wanting to avoid fungal decay. In Denmark, houses can be insured against fungal decay. Moulds affect both indoor climate and people and can cause a range of different health problems, such as allergies and infections. They produce large numbers of spores as well as volatile organic compounds. Mould growth can be controlled by steam treatment and the use of different disinfectants.

\section{Keywords:}

fungal decay, biodeterioration, biodegradation, wood protection, insurance, indoor climate
\end{abstract}

\section{THE CYCLE IN NATURE}

In nature a number of organisms are able to transform solar energy into chemical energy (Figure 1). This process takes place in the chloroplasts, which contain chlorophyll, where carbon dioxide and water are transformed into sugar and oxygen is released. The sugar is the basis for the formation of hemicellulose, cellulose and lignin, which are used by plants to build their wood, leaves etc (Figure 2). Other organisms do not have chlorophyll, but instead gain energy by breaking down plant material, which contains the stored solar energy. The energy is released under production of carbon dioxide and water, thus completing the natural cycle. The organisms which can store solar energy belong primarily to two kingdoms: Chromista and Plantae (marked green in Figure 3), while those which live from breaking down organic matter belong to: Bacteria, Animalia, Protozoa and Fungi (marked orange in Figure 3). 


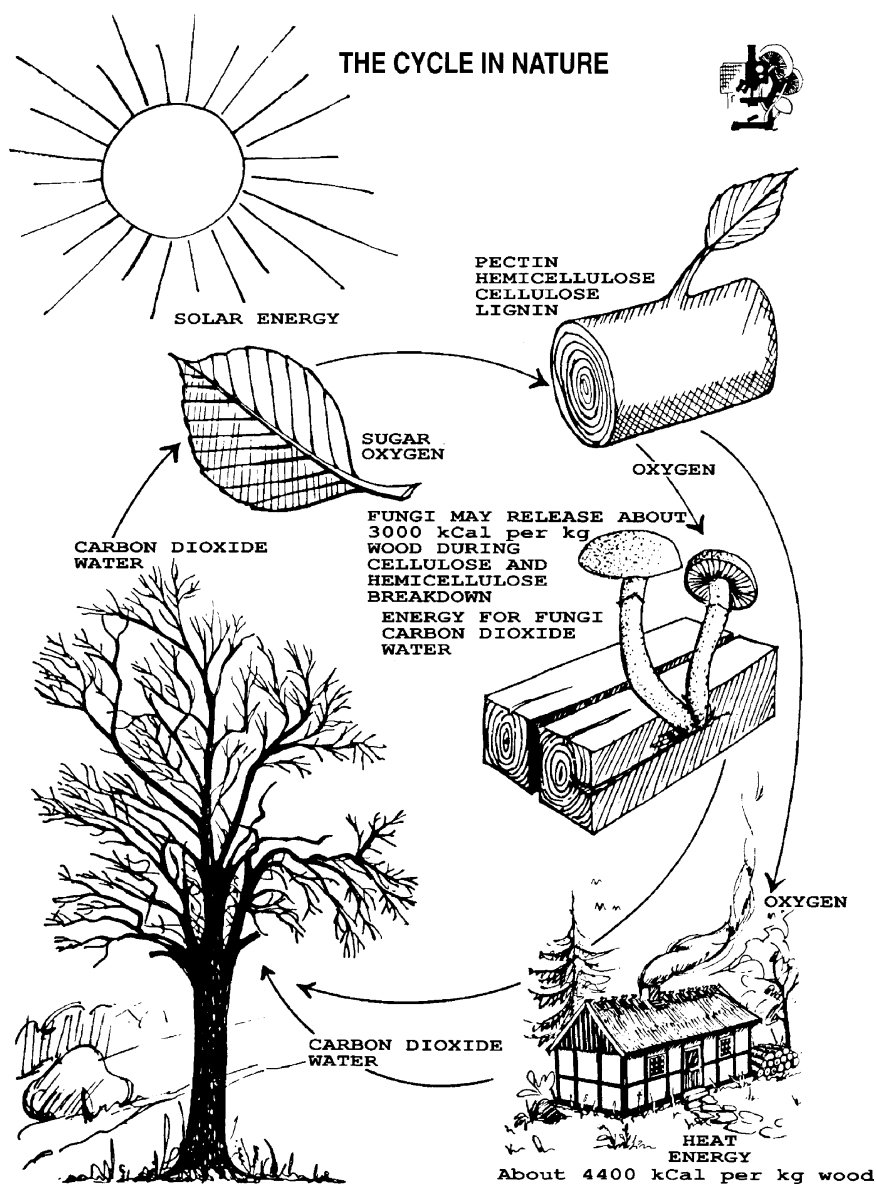

Figure 1: The cycle in nature including production and breakdown of organic compounds

\section{BIODEGRADATION AND BIODETERIORATION}

Contrary to other languages, English has two words for biological breakdown. One is biodegradation, which is a term used to describe the 'desirable' or natural breakdown in nature. The other is biodeterioration, which is used to describe the 'undesirable' breakdown of building materials in houses.

In nature it is important that all dead plants and animals are broken down quickly and re-enter the natural cycle (biodegradation), but in building materials the breakdown (biodeterioration) should be postponed for as long as possible. For example, a fence should last 30 years, a villa maybe 100 years and a church or castle maybe 1,000 years.

Background to fungi and bacteria

\section{FUNGI AND BACTERIA}

Fungi and bacteria are microscopic one or multi-celled decay organisms which are able to release the solar energy from organic materials. Among the basidiomycetes are many wood-decaying fungi capable of breaking down the timber in houses. They cause huge problems with the stability of timbers when they transform the cellulose to sugar, which they absorb and combust internally. Many ascomycetes and zygomycetes in addition to 


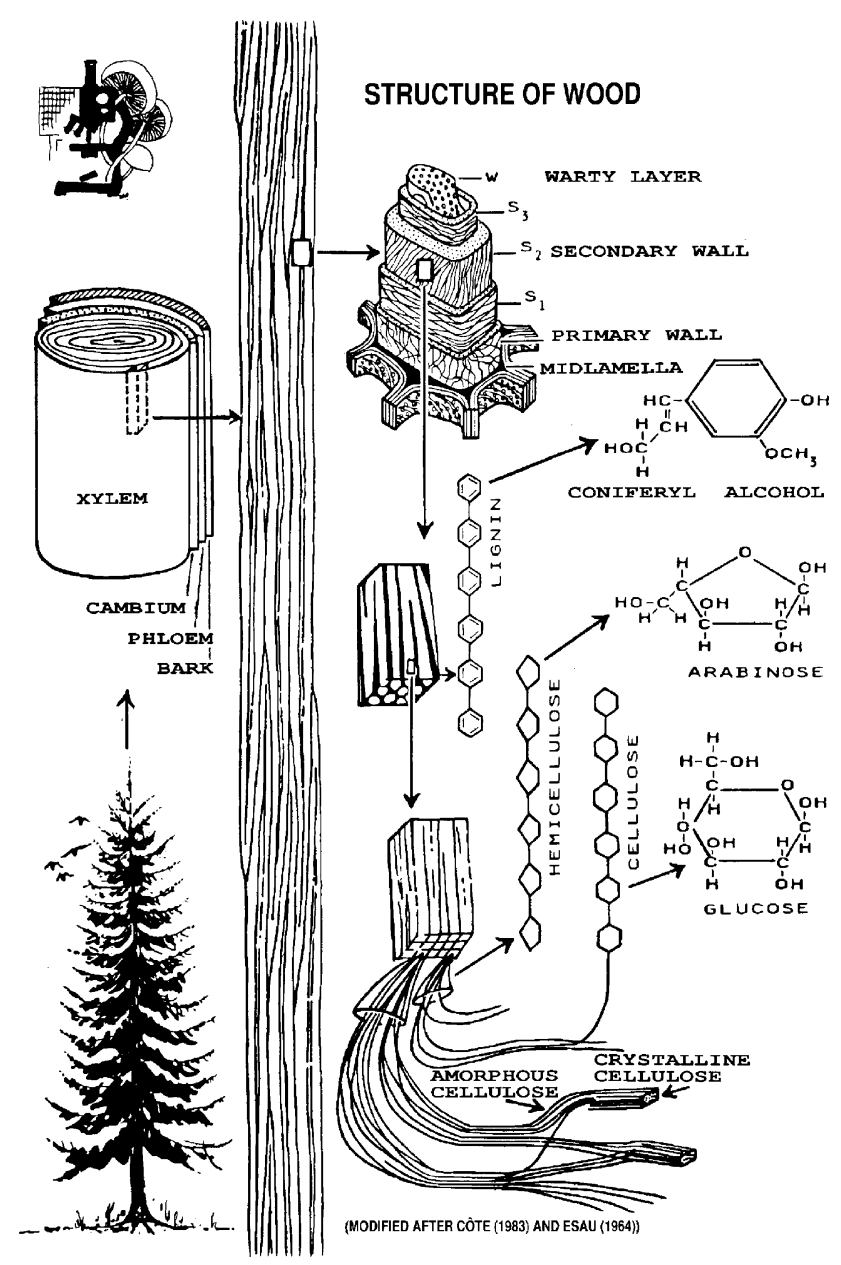

Figure 2: The morphological and chemical structure of wood

their sexual stage have an asexual stage in their life cycle in which they produce huge numbers of spores (conidia) (Figure 4). This stage produces those moulds which are responsible for some of the indoor climate problems known as Sick Building Syndrome (SBS). Moulds are caused by some water-soluble and gaseous secondary metabolites produced by the fungi in their struggle for life. Bacteria may produce endotoxins, which may also cause health problems.

\section{Protection}

\section{TYPES OF PROTECTION}

\section{Wood protection}

How can one protect the organic materials in buildings from breakdown? First, one must learn the demands of fungi and bacteria (the important wood-decaying organisms), with regard to temperature, light, moisture and nutrients and then avoid fulfilling them. Sometimes it is inevitable that these demands are met and then substances must be used that are toxic to the microorganisms involved, ie so-called fungicides. 


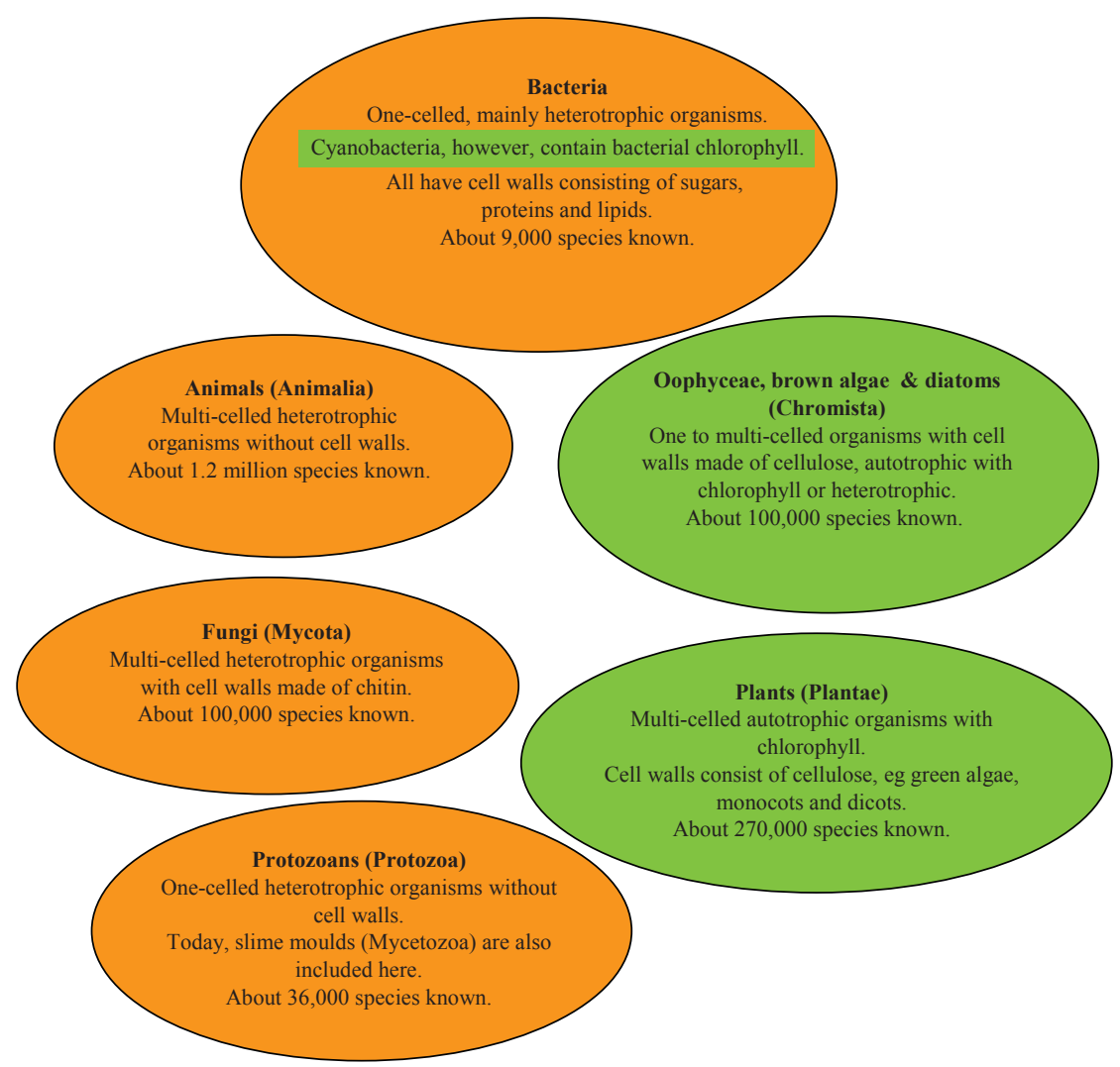

Figure 3: The six kingdoms of life

\section{Other sources of moisture in buildings}

\section{Moisture conditions}

Building materials may become moistened in different ways. Wood absorbs moisture from the air and goes into equilibrium with the relative air humidity of the surrounding air. A relative air humidity of 45 per cent equals 9 per cent wood moisture content and is sufficient for attacks of House Longhorn Beetles and House Dust Mites indoors in carpets and bed linen (Figure 5). Mould infections start when the air humidity rises to 70 cent, which equals 14 per cent wood moisture content, while wooddecaying fungi need more than 87 per cent relative air humidity or 20 per cent wood moisture content to get started.

Other sources of moisture in buildings are rising damp from the ground, leaking roofs, down-pipes and soil pipes as well as condensation on cold building parts. High air humidity can account for up to 30 per cent wood moisture content, but may be as high as 150 per cent in newly cut trees or even 300 per cent in completely water-soaked timber, such as pile foundations or poles in jetties.

Most fungi die at a wood moisture content of about 90 per cent when the oxygen supply becomes too low. Lord Nelson used this fact when dry rot or other wood-decaying fungi attacked his ships by simply sinking them and leaving them for half a year on the bottom of the sea, after which time the fungi were dead. Afterwards, naturally, the ships had to be dried out thoroughly. 

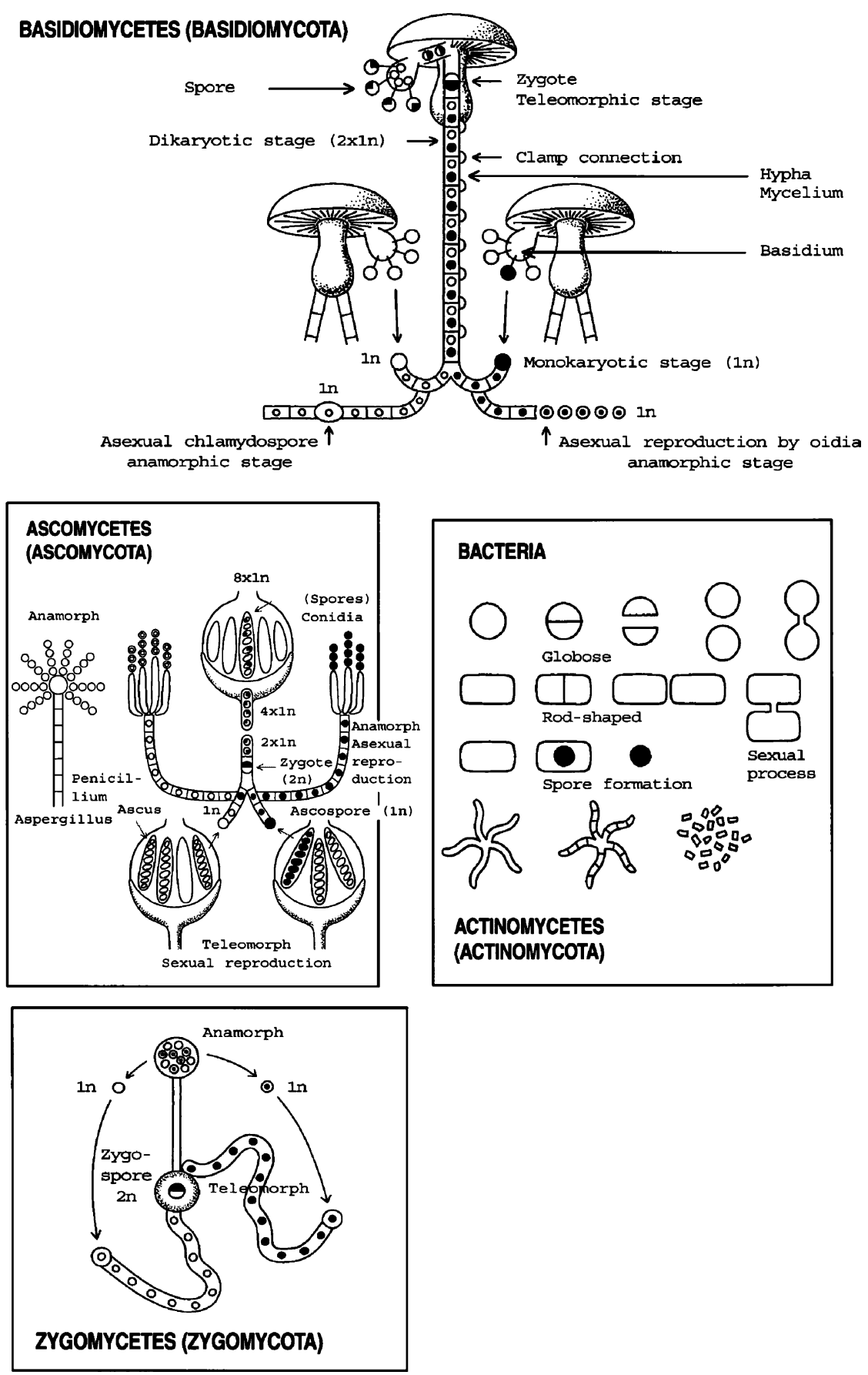

Figure 4: The main systematic groups of fungi and bacteria with schematic life cycles and microscopic features

Fungi have different demands for moisture (Table 1). For example, the dry rot fungus, Serpula lacrymans, can make do with 20 per cent wood moisture content and dies from lack of oxygen at 50 per cent. The polefungus, Physisporinus vitreus, on the other hand prefers between 50-90 per cent wood moisture content. This means that the wood moisture content together with other factors govern which species will 


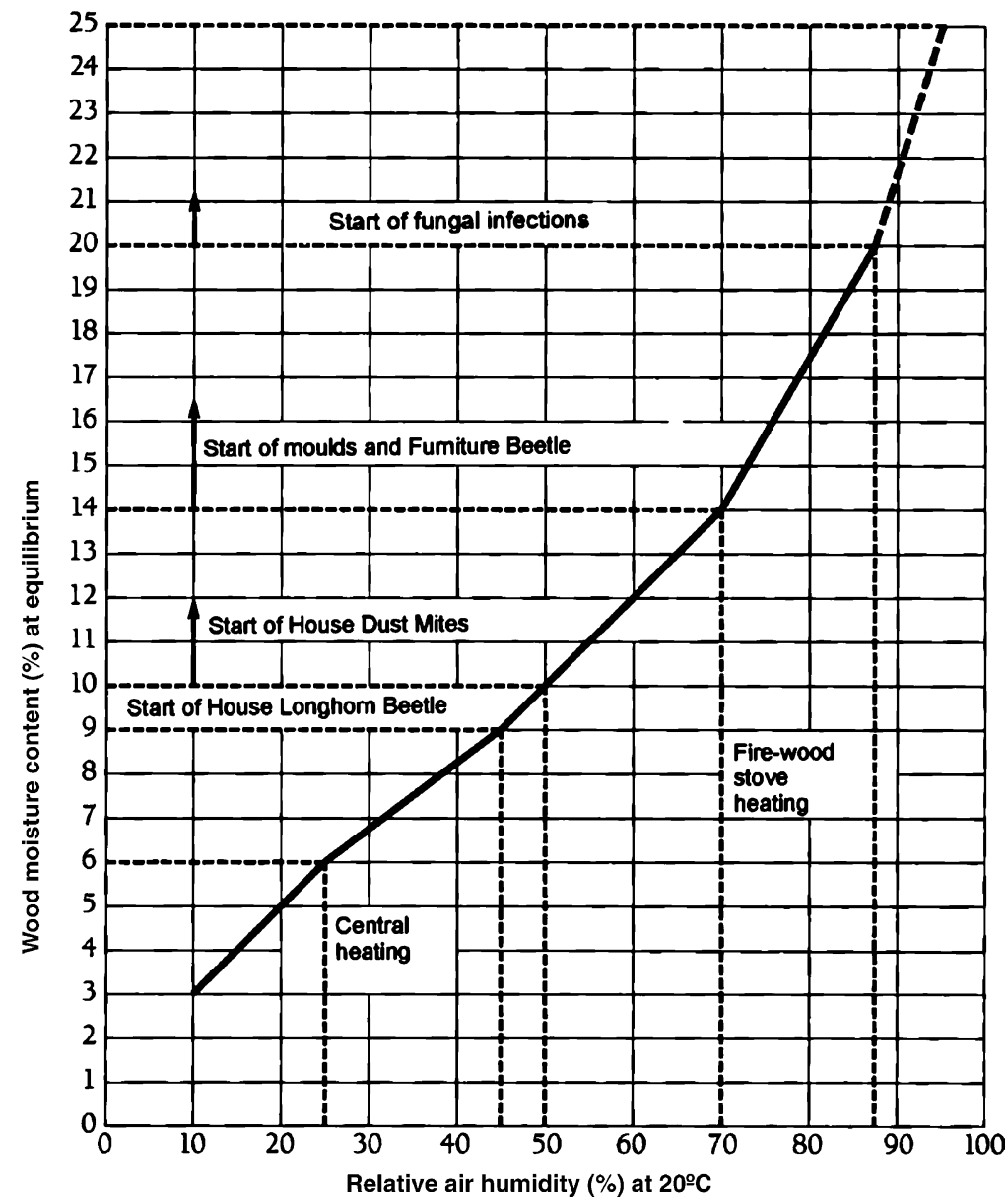

Figure 5: The relation between air humidity and wood moisture content at $20^{\circ} \mathrm{C}$, showing critical levels for outbreaks of mould infections and wood-decaying fungi

Table I: The moisture content of the wood determines which fungi are able to grow in a certain place

\begin{tabular}{llc}
\hline \multirow{2}{*}{ Species } & \multicolumn{2}{c}{ Wood moisture content (\%) } \\
\cline { 2 - 3 } & Optimum & Lethal \\
\hline Dry rot & $20-30$ & $>50$ \\
Cellar fungus & $30-55$ & $>80$ \\
White polypore & $35-55$ & $>85$ \\
Crust fungi & $50-60$ & $>90$ \\
Stalkless paxillus & $30-70$ & $>90$ \\
Polefungus & $50-80$ & $>90^{*}$ \\
\end{tabular}

Notes: *Survives by means of sclerotia.

grow in the house. Table 1 shows the optimum and lethal values for some common fungi in houses.

\section{Constructive protection}

A sensible house construction in many cases is sufficient to protect it from fungal infections. Some examples include an effective damp-proof course 
between foundations and masonry, wide eaves to protect facades and windows with a well-ventilated aluminium glazing batten. Maintenance of gutters, down-pipes, soil pipes and sewers is also very important.

\section{Chemical protection}

An effective constructive protection is not always possible, especially when architects scamper about with pergolas, protruding joist ends and fancy window constructions. In these cases chemical protection becomes necessary.

Nowadays, water-soluble fungicides such as copper and propiconazole are used for joists and other constructional timbers. Fungicides such as propiconazole and IPBC with organic solvents such as turpentine are used for window constructions to prevent the timber from warping.

Historically, copper, chromium and arsenate (CCA) were used for pressure impregnation. There are huge problems with toxic waste when the timber is no longer in use, however, as it cannot be burned or broken down by fungi.

Tin compounds were formerly used for vacuum impregnation, especially in windows; however, the widespread use of tin in ship's paint to prevent algal growth has caused environmental damage in the sea and harbours. The use of tin is now banned in Denmark.

\section{Fungal insurance}

In Denmark it is possible to insure houses against fungal decay. Only damages that have evolved in a short period, causing failure of constructions, are covered by the insurance, however, ie so-called 'fungal damage'. A slowly developed weakening of constructions over several years is regarded as a consequence of bad maintenance and is not covered

'Rot damage'

\section{Temperature also determines the growth of fungi} by the insurance, this is so-called 'rot damage'.

\section{Temperature conditions}

Besides the wood moisture content, temperature also determines the growth of fungi. The true dry rot fungus, Serpula lacrymans, has an optimum temperature of about $20^{\circ} \mathrm{C}$, freezes to death at $-10^{\circ} \mathrm{C}$, stops growing at $25^{\circ} \mathrm{C}$ and dies when exposed to $37^{\circ} \mathrm{C}$ for 10 minutes (Table 2). These facts can be used in the control of dry rot by heating the infected

Table 2: The vital functions of fungi are dependent on temperature and the minimum, optimum and lethal temperatures of some common wood-decaying fungi are seen in this table

\begin{tabular}{llll}
\hline Species & & Temperature ( ${ }^{\circ}$ C) & \\
\cline { 2 - 4 } & Minimum & Optimum & Lethal \\
\hline Dry rot & ca. -10 & ca. 20 & ca. 37 \\
Cellar fungus & ca. -30 & ca. 23 & ca. 65 \\
White polypore & ca. -30 & ca. 28 & ca. 80 \\
Yellow-red gill polypore & ca. -30 & ca. 35 & ca. 80 \\
Stalkless paxillus & ca. -30 & ca. 28 & ca. 65 \\
Crust fungi & ca. -30 & ca. 30 & ca. 65 \\
\hline
\end{tabular}




\section{Correct delimitation of dry rot from other fungi is very important}

construction either by means of hot air or microwaves. In Denmark microwaves have been used in about 5,000 cases and hot air treatment in about 100 cases. These methods can lower the cost of repairs considerably.

Other wood-decaying fungi cannot be controlled by heating without the danger of fire in the building because they can withstand much higher temperatures than dry rot (Table 2). In the hot air treatment of dry rot, temperatures of about $80^{\circ} \mathrm{C}$ are used in order to reach the lethal temperature quickly.

\section{IDENTIFICATION OF FUNGI}

At Hussvamp Laboratoriet (laboratory for the study of dry rot and other fungi in buildings) every year about 6,000 wood samples are examined and a mycologist identifies the fungi responsible for the decay. Correct delimitation of dry rot from other fungi is very important as it requires a different and more thorough treatment. The cause for this is its ability to penetrate and destroy both wood and mortar. Therefore, both masonry and timber have to be treated with fungicide and pressure-impregnated wood used, to ensure that reinfections do not occur. A very small amount of dry rot mycelium is sufficient for reinfection, so treatment has to be very thorough when delimiting the extent of the infection.

Moulds are also identified to genus and species, so that doctors can screen the inhabitant for allergy against the fungi found in their homes by means of prick or blood tests.

\section{Examples of wood-decaying fungi}

The search for fungi can be started in cool and moist cellars, later moving on to the warmer areas further up into the building. Most wood-decaying fungi in houses belong to the basidiomycetes.

The most common wood-destroying fungus in houses is cellar fungus (Coniophora puteana), which is found in 50 per cent of all samples (Figure 6). The English common name 'cellar fungus' describes well where it is found; however, it is not confined to cellars, but may also be

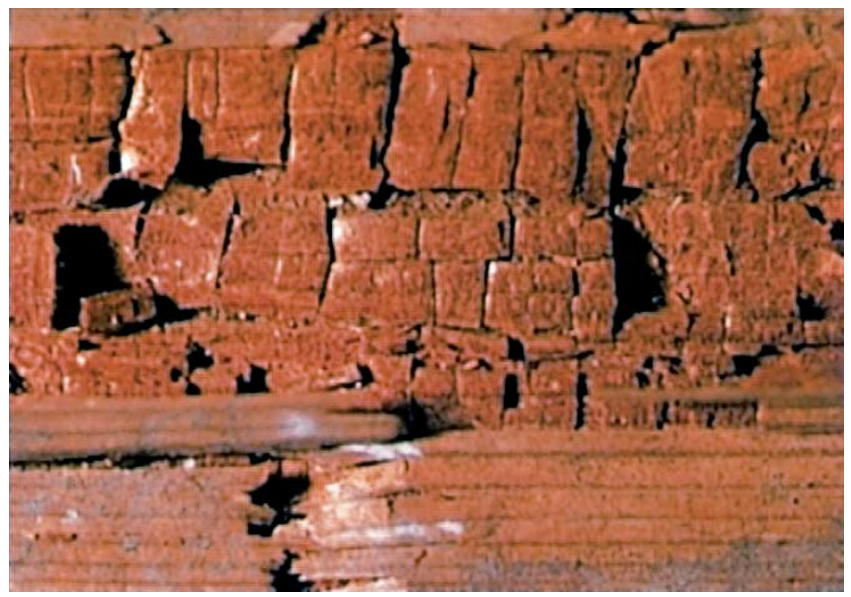

Figure 6: Wood decayed as a brown rot by the cellar fungus Coniophora puteana 
True dry rot fungus is most destructive species in houses found in floor partitions, wherever timber is inserted into moist masonry and in roof timber under leaking roofs. Infected wood becomes brown with cracks both along and across the grain, a so-called cubical or brown rot. The cross-cracks are about $1 \mathrm{~cm}$ apart in this species. Fruitbodies, which are flat, brown with a white margin and appressed to the substrate, are rarely seen. Repair of damages starts with elimination of the moisture source and then infected timber is cut off $10 \mathrm{~cm}$ outside the last visible decay and replaced by pressure-impregnated timber. The surrounding timber should be impregnated with a fungicide, eg Protox Svamp or Boracol $10 \mathrm{Rh}$.

The most destructive species in houses is the true dry rot fungus (Serpula lacrymans), which is often found in cellars or other places with moist masonry (Figure 7). The species requires some kind of calcium nearby, often in the form of mortar or concrete, which it is able to penetrate. This ability makes it very difficult to control, as it can hide in the masonry and reinfect the timber from there unless properly treated. The surface mycelium is either greyish and skin-like or cord-like. The latter enables the fungus not only to spread quickly across a surface but also to transport water up to $6 \mathrm{~m}$ from a moisture source. The infected timber becomes greyish and shows a brown rot with cross-cracks every $5-7 \mathrm{~cm}$. Fruitbodies are commonly found and have a diameter of $20-50 \mathrm{~cm}$ with a red-brown folded surface and a thick white margin. They are usually appressed to the substrate, but sometimes form shelf-like structures. Huge numbers of spores are released from the fruitbody and can be seen as a red-brown powder on the floor. In repairs, a safety-zone of $1 \mathrm{~m}$ is cut off around the visibly infected timber. The remaining timber and wall surfaces are treated with one of the above-mentioned fungicides in order to isolate the mycelium inside the wall. Replacement timber should be pressure impregnated. The mycelium dies at temperatures

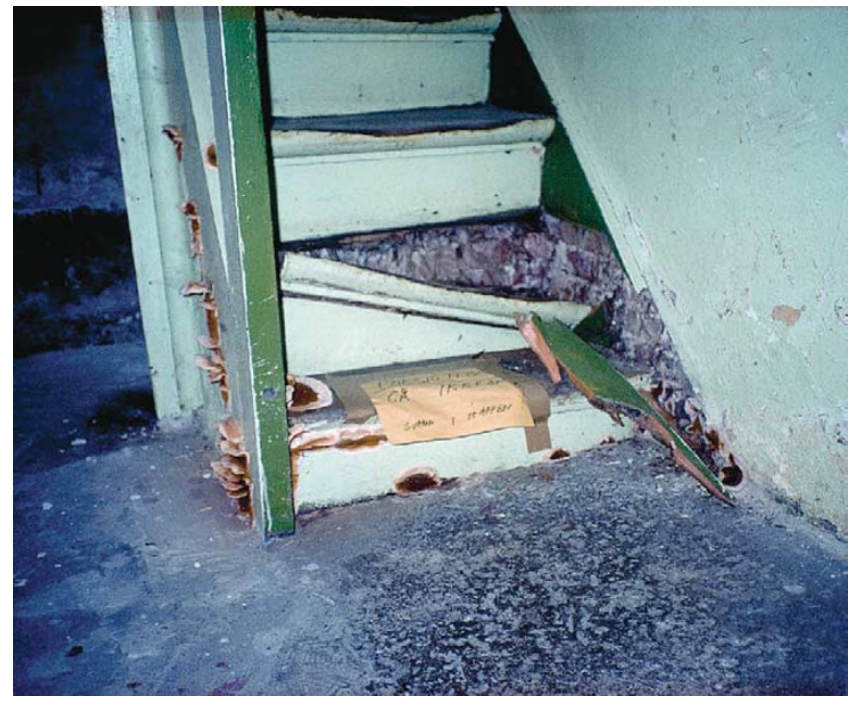

Figure 7: Fruiting bodies of the dry rot Serpula lacrymans breaking out on a totally decayed staircase in a cellar 


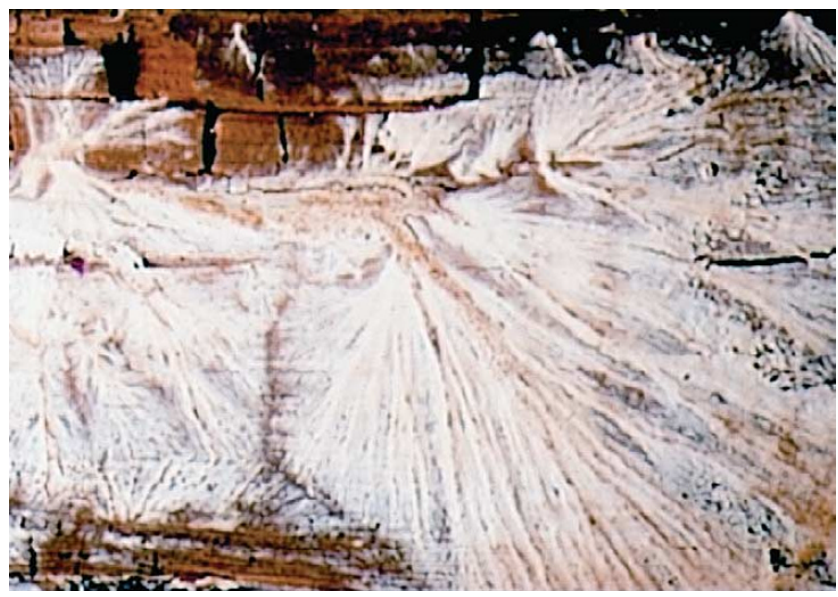

Figure 8: Fan-shaped strandmycelium of the mine polypore Antrodia vaillantii on the surface of decayed timber showing a brown rot

above $37^{\circ} \mathrm{C}$ so other possible repair methods are heat treatment with either microwaves or dry hot air.

White polypores are a complex species belonging to the genus Antrodia, which have a white surface mycelium and fruitbodies with pores. The fungus often hides inside the wood and the infection is therefore first detected when fruitbodies appear on the surface. The white polypore (Antrodia sinuosa) is heat-tolerant and therefore often found under bathrooms and in hot roof constructions. Another species, the mine polypore (Antrodia vaillantii), is found in mines and cellars (Figure 8). Repair of damages caused by this fungus is similar to that for cellar fungus.

Large parts of the old city in Copenhagen were built on pile foundations. The polefungus (Physisporinus vitreus) is a polypore often found in the upper part of the piles when the groundwater level is lowered due to sewerage (Figure 9). Just like other fungi it will die at a wood moisture content above 90 per cent, but it has a special structure known as sclerotia which enables it to survive. It is made of small balls of hyphae surrounded by a bark, and when the water level drops it is able to germinate and attack new timber. The decayed timber has a reddish colour

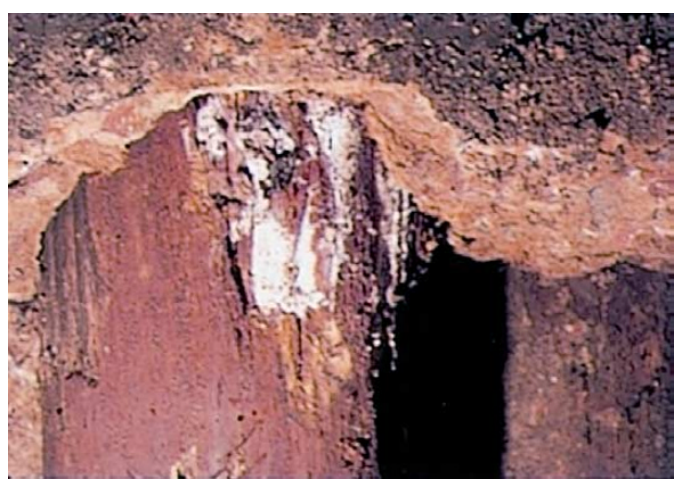

Figure 9: Top of a pole from a pile foundation showing attack by the polefungus Physisporinus vitreus 


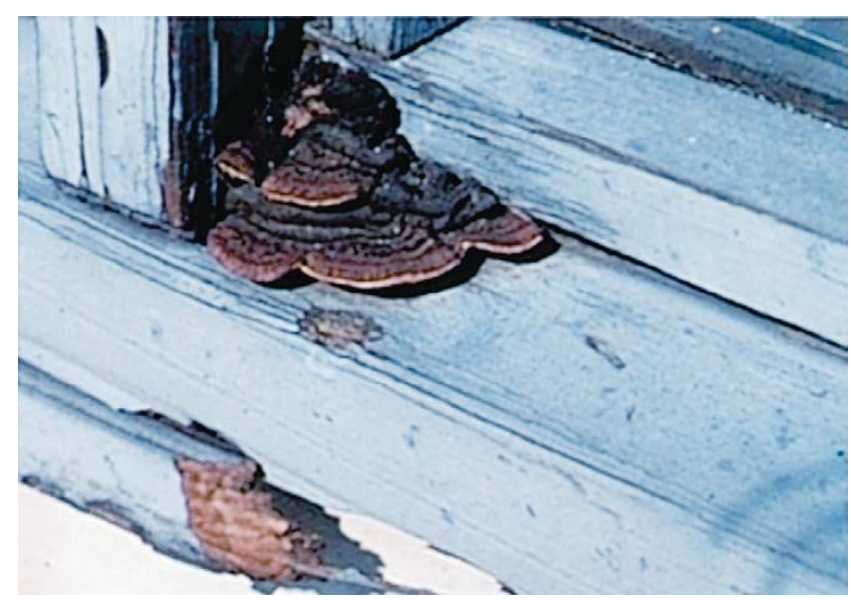

Figure 10: Fruiting bodies of the yellow-red gill polypore Gloeophyllum sepiarium breaking out externally on a window frame

and the consistency of the flesh of an orange. Its fruitbodies are rarely found in houses.

In the hotter areas of the house yellow-red gill polypore (Gloeophyllum sepiarium) are found (Figure 10). This fungus can be found in blackpainted window timbers, under build-up roofs and in log cabins, where it can do much damage. The surface mycelium is red-brown and the decayed wood shows a dark-brown rot with $2 \mathrm{~mm}$ between cross-cracks.

Fruitbodies are shelf-like with a brown tomentose upper side and gill-like pores below.

Crust fungi (Corticiaceae) like very damp conditions. The infection is often not found until fruitbodies appear on the surface. They are often white, flat and appressed to the wood surface, looking like white paint that has been spilled. After poking into the wood with a knife one will see that the fungus is whitish and strongly fibrillose, hence the term white rot in contrast to the brown rot described above.

\section{Moulds can cause problems with indoor climate}

\section{MOULDS AND INDOOR CLIMATE}

While the basidiomycetes mentioned above directly weaken the timber with constructional failure as a consequence, moulds do not affect the strength of timbers. They may cause problems with indoor climate, however, such as unpleasant smells and SBS for the inhabitants. Moulds produce both water-soluble secondary metabolites (eg penicillin) and volatile organic compounds which may cause headaches and respiratory diseases. People with mould problems are only rarely able to smell it themselves. They get used to the smell, which is so obvious to others when it clings to clothes and furniture.

In nature there is sometimes a high concentration of mould spores (conidia) in the air, but it varies according to the time of year. In February, about 1,000 spores per $\mathrm{m}^{3}$ of air can be measured, but in August when plants and fruits are rotting, ie being infected by moulds, the spore count increases to 10,000 spores per $\mathrm{m}^{3}$. 


\section{Indoor moulds}

The mould problem indoors in Denmark started during the oil crisis in the 1970s when room temperatures had to be lowered and the houses were made more airtight in order to avoid heat loss. This in turn meant higher air humidity and too little ventilation. Mould growth is often found when humid air condensates on cold outer walls. Moulds are very fond of glue and wallpaper, on which they produce dark stains that smell bad and cause the symptoms of SBS. Indoors it is preferable to keep the spore concentrations in the air below the outdoor level and preferably below 3,000 spores per $\mathrm{m}^{3}$.

\section{Examples of indoor moulds}

There are a number of mould species that occur indoors in connection with water damage in houses.

Penicillium chrysogenum is used in the production of penicillin, but apart from that it also produces some toxic secondary metabolites, known as mycotoxins. The spores (conidia) are formed at the tip of finger-like sporophores (Figure 11). Long-term exposure to high concentrations of spores can make people so hypersensitive that they have to move house.

Aspergillus versicolor is often called 'the watering can mould' due to the resemblance of the sporophores with their chains of conidia to a spraying watering can (Figure 12). This species produces mycotoxins as well as a bad smell, and there is a risk of hypersensitivity when people are exposed to its spores.

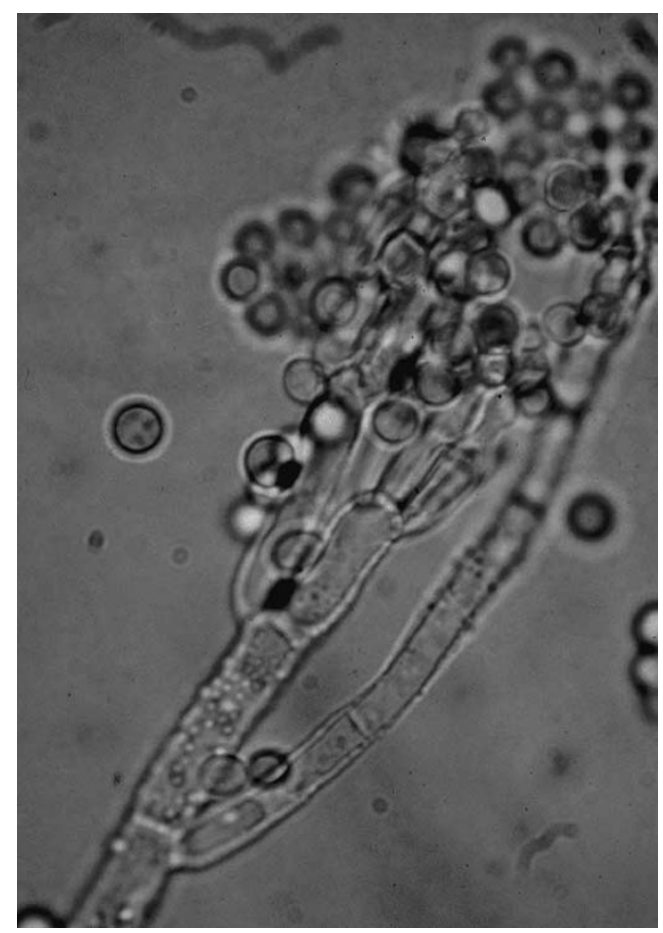

Figure 11: Penicillium chrysogenum, a mould with a branching sporophore, seen under the light microscope 


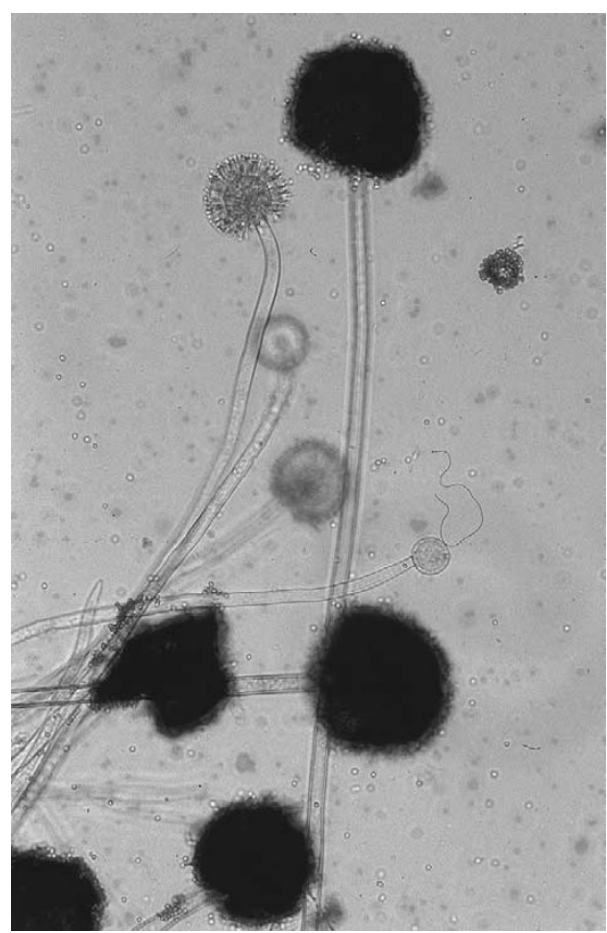

Figure 12: Aspergillus versicolor, a mould with pin-shaped sporophores, seen under the light microscope

Stachybotrys chartarum is often found on gypsum boards, while the above-mentioned species are more common on wallpaper. It produces some highly toxic compounds and therefore must be eliminated as soon as possible.

\section{CONTROL OF MOULD GROWTH}

The first step in mould control is elimination of the moisture source and drying out of the construction. Then, wallpaper and glue must be removed thoroughly. Walls should be treated with a disinfectant, eg containing hypochlorite or benzalkonium chloride, or sterilised with superheated steam. Cases with lasting moisture problems can be impregnated with a fungicide such as Boracol $10 \mathrm{Rh}$ with sodium octaborate or Protox Skimmel with propiconazole and IPBC.

\section{Further reading}

Bech-Andersen, J. (1995) The Dry Rot Fungus and Other Fungi in Houses, Hussvamp Laboratori et Forlag, Holte, Denmark.

Bech-Andersen, J. (2004) Indoor Climate and Moulds, Hussvamp Laboratoriet, Holte, Denmark. 